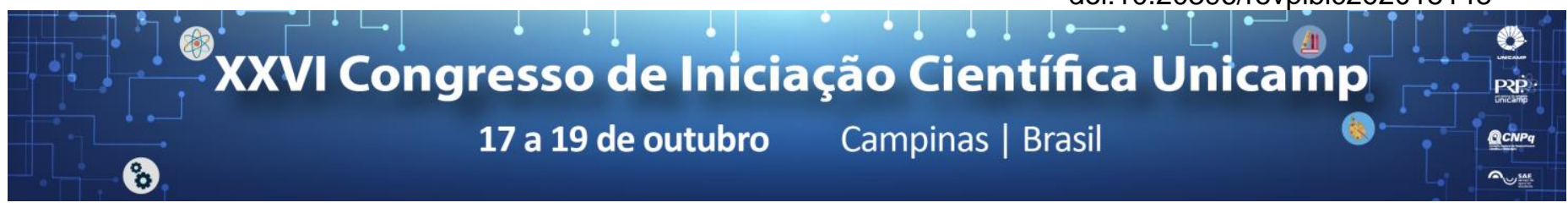

\title{
Estudo de um índice linear para a estimativa da margem de estabilidade de tensão de sistemas elétricos de potência.
}

\section{André Mendonça Boni*, Carlos A. Castro}

\section{Resumo}

Este trabalho tem por objetivo realizar o estudo de um índice de estabilidade de tensão, chamado de M-index, cujo comportamento é linear em relação à demanda de potência. $\mathrm{O} M$-index pode ser utilizado para estimar a margem de estabilidade de tensão de maneira direta e eficiente. Além disso, o $\mathrm{M}$-index permite identificar as barras mais fracas da rede com relação a instabilidades de tensão. Os resultados demonstram que o $\mathrm{M}$-index é de fato linear com o aumento de carga e é possível estimar com sucesso a margem de carga.

\section{Palavras-chave:}

Sistemas de potência; Operação; Estabilidade de tensão.

\section{Introdução}

A condição de operação do ponto de vista da estabilidade de tensão é uma preocupação importante na operação e no planejamento de sistemas elétricos de potência. Devido a cenários econômicos e ambientais, as empresas do setor elétrico têm hoje filosofias de operação baseadas em utilizar seus equipamentos próximos de seus limites operacionais, podendo levar a problemas de estabilidade de tensão.

Vários índices de estabilidade de tensão já foram propostos na literatura e alguns são calculados com base na comparação da impedância de Thévenin com a impedância da carga em uma determinada barra para a determinação da margem de estabilidade de tensão.

No entanto, a variação deste tipo de índice é não linear e, portanto, este comportamento não é desejado já que dá ao operador de rede uma sensação falsa de segurança e oferece uma margem de manobra muito pequena para o operador de rede acionar os esquemas de controle para manutenção da estabilidade. Um índice linear pode auxiliar neste problema de maneira apropriada, já que a linearidade pode ser usada para determinar a margem do sistema e fornecer ao operador informações mais claras sobre o estado da rede.

O objetivo é reproduzir os resultados de avaliação da margem de estabilidade de tensão apresentados em [1], utilizando o índice linear (M-index) proposto, para redes de potência de pequeno e médio portes.

\section{Resultados e Discussão}

A Figura 1 mostra o diagrama unifilar e o diagrama fasorial de uma rede de potência simples de duas barras, para a qual " $E=1$ pu" e " $Z=1$ pu". O comportamento do M-index para a rede é mostrado na Figura 2.

Observa-se que os índices valem 1 para carga nula e chegam a zero quando a carga é igual à carga crítica. Ambos evoluindo de forma aproximadamente linear para cargas pequenas, mas somente o M-index mantém a característica linear.

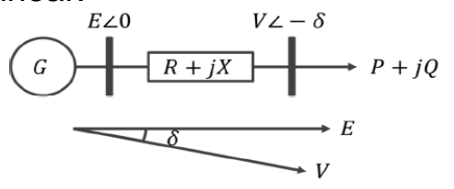

Figura 1. Rede exemplo de duas barras [1].

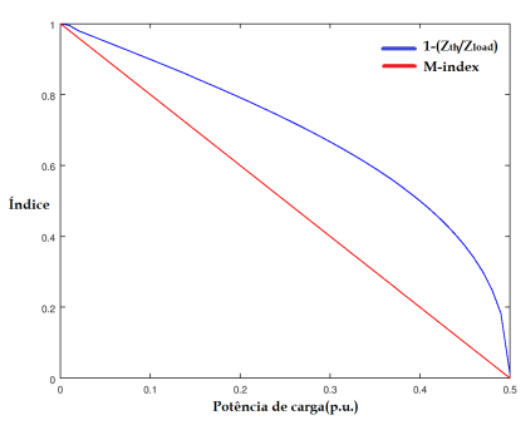

Figura 2. Comportamento do índice M-index obtido para variação da carga em uma rede de 2 barras (Figura 1).

A Figura 3 mostra o comportamento observado do $\mathrm{M}$ index para o caso da rede IEEE-30 barras. De forma semelhante ao caso de duas barras, o M-index permanece linear para todos os valores de carga (carga zero até a crítica).

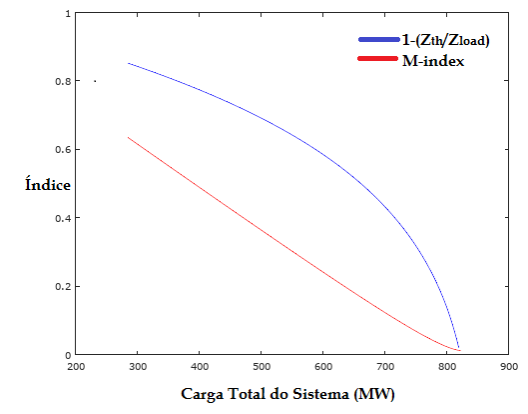

Figura 3. Comportamento do índice M-index obtido para variação da carga na rede IEEE-30 barras.

\section{Conclusões}

No projeto foi estudado e aplicado um índice de estabilidade de tensão que é linear com a variação da carga [1] é apresentado e a sua linearidade foi verificada para um sistema de duas barras.

Para avaliar a generalidade do M-index e a metodologia multimodal através do equivalente multi-portas, o índice foi testado no sistema IEEE-30 barras e comparado com um índice de estabilidade de tensão existente. Os resultados estão de acordo com o modelo.

1 A.R.R. Matavalam, V. Ajjarapu, Calculating the Long Term Voltage Stability Margin using a Linear Index, IEEE PES General Meeting, 2015. 